\title{
Continuous stand-alone controllable aerosol/cloud droplet dryer for atmospheric sampling
}

\author{
S. Sjogren, G. P. Frank, M. I. A. Berghof, and B. G. Martinsson \\ Division of Nuclear Physics, Lund University, Lund, Sweden \\ Correspondence to: S. Sjogren (staffan.sjogren@yahoo.com) \\ Received: 30 May 2012 - Published in Atmos. Meas. Tech. Discuss.: 8 August 2012 \\ Revised: 18 January 2013 - Accepted: 22 January 2013 - Published: 13 February 2013
}

\begin{abstract}
We describe a general-purpose dryer designed for continuous sampling of atmospheric aerosol, where a specified relative humidity $(\mathrm{RH})$ of the sample flow (lower than the atmospheric humidity) is required. It is often prescribed to measure the properties of dried aerosol, for instance for monitoring networks. The specific purpose of our dryer is to dry cloud droplets (maximum diameter approximately $25 \mu \mathrm{m}$, highly charged, up to $5 \times 10^{2}$ charges). One criterion is to minimise losses from the droplet size distribution entering the dryer as well as on the residual dry particle size distribution exiting the dryer. This is achieved by using a straight vertical downwards path from the aerosol inlet mounted above the dryer, and removing humidity to a dry, closed loop airflow on the other side of a semi-permeable GORE-TEX membrane (total area $0.134 \mathrm{~m}^{2}$ ).

The water vapour transfer coefficient, $k$, was measured to be $4.6 \times 10^{-7} \mathrm{~kg} \mathrm{~m}^{-2} \mathrm{~s}^{-1} \% \mathrm{RH}^{-1}$ in the laboratory (temperature $294 \mathrm{~K}$ ) and is used for design purposes. A net water vapour transfer rate of up to $1.2 \times 10^{-6} \mathrm{~kg} \mathrm{~s}^{-1}$ was achieved in the field. This corresponds to drying a $5.7 \mathrm{~L} \mathrm{~min}^{-1}\left(0.35 \mathrm{~m}^{3} \mathrm{~h}^{-1}\right)$ aerosol sample flow from $100 \% \mathrm{RH}$ to $27 \% \mathrm{RH}$ at $293 \mathrm{~K}$ (with a drying air total flow of $\left.8.7 \mathrm{~L} \mathrm{~min}^{-1}\right)$. The system was used outdoors from 9 May until 20 October 2010, on the mountain Brocken $\left(51.80^{\circ} \mathrm{N}\right.$, $10.67^{\circ} \mathrm{E}, 1142 \mathrm{~m}$ a.s.1.) in the Harz region in central Germany. Sample air relative humidity of less than $30 \%$ was obtained $72 \%$ of the time period. The total availability of the measurement system was $>94 \%$ during these five months.
\end{abstract}

\section{Introduction}

Atmospheric aerosol is important for climate. Large efforts are done to systematically investigate and monitor its properties. Many aerosol properties vary with relative humidity (RH). For measurements, and especially for data quality concerns for comparisons between stations/networks, a dry aerosol is important. Aerosol dryers and the drying process have been described previously (e.g. Martinsson et al., 1992). An automatically regenerating dryer has recently been presented by Tuch et al. (2009); see references therein for additional drying methods. That dryer used a three-way valve alternating between two silica gel dryers. Transmission for that system was well characterized in the diameter size range from 3 to $800 \mathrm{~nm}$. The $50 \%$ transmission for larger particles was calculated at $6 \mu \mathrm{m}$ diameter. In our application we want to extend the aerosol measurement size range to drying of larger particles and cloud/fog droplets up to $25 \mu \mathrm{m}$ diameter, which require a straight vertical path, in order to reduce impaction and sedimentation losses. This excludes the use of a standard valve or tee. The dryer should also work continuously. Therefore the design presented in this paper was used. In addition, the drying airflow rate can be varied to maintain a set RH (lower than ambient) in the sample flow, should that be required (in the future an additional humidifying setup can also be envisaged to maintain constant say $25 \% \mathrm{RH})$. A closed loop for the drying air was designed for minimum variability due to flow changes and gas transfer into the aerosol sample flow. 


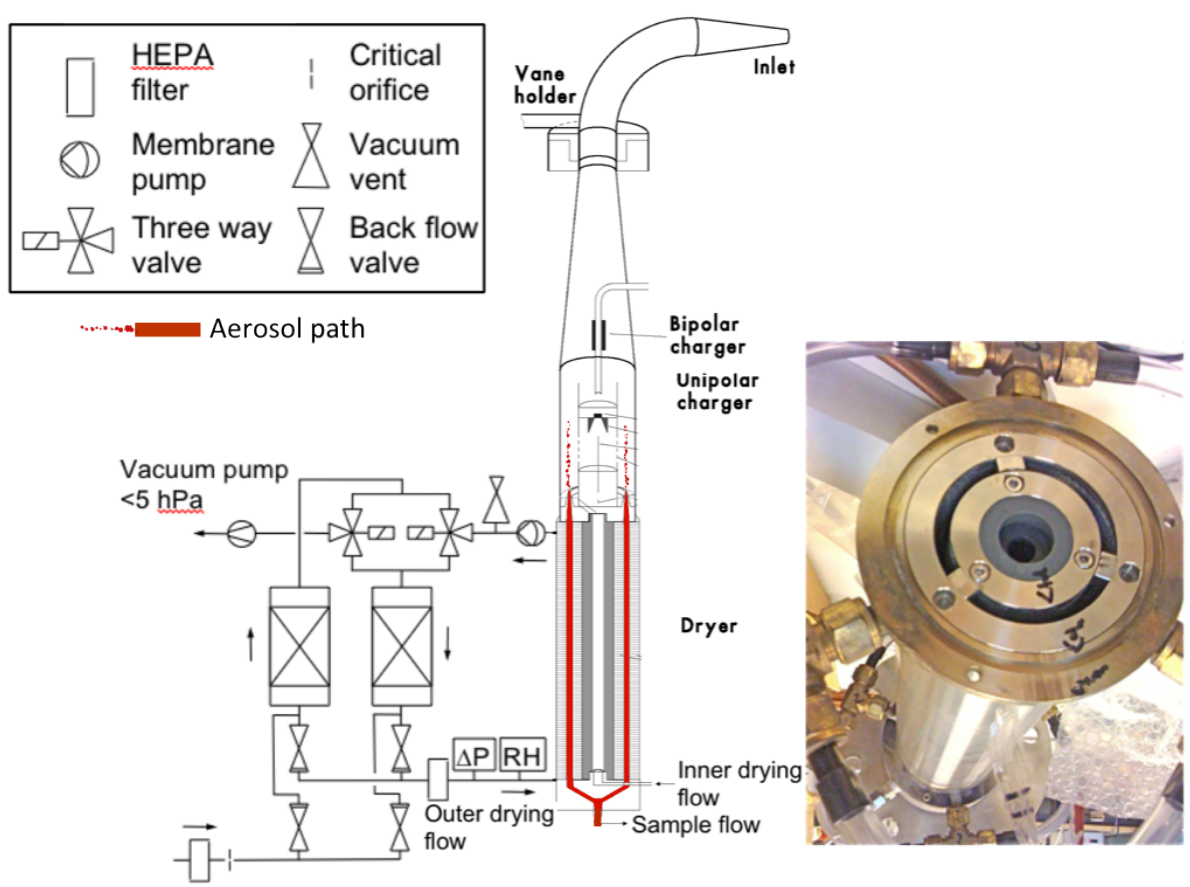

Fig. 1. Schematic drawing of the inlet part of the DAA with dryer and dry air regeneration system of the outer drying air (left panel) and photo of the entry to the dryer only (right panel). The aerosol sample flows downwards into the three slots; the metal nets are visible on the inside of the slots. The central circular hole is for the exit flow of the inner drying airflow. Further details of the inlet, situated above the dryer, are found in Frank et al. (2004).

\section{Materials and methods}

Below the criteria for designing a dryer are detailed, as well as the method to measure the particle transmission and the water vapour removal of the dryer.

\subsection{Design criteria}

The main principle of the dryer is to dry sample air flowing vertically downwards in counterflow with dry airflows, these flows being separated by membranes. Two concentric, cylindrical membranes were used, with the sample flow in the middle, annularly, between the dry airflows (see Fig. 1). The membrane is needed due to different flow velocities and flow directions of sample flow and drying flow, which would otherwise result in mixing between the two. The membrane allows water vapour exchange by diffusion, but no particle transfer. The two dry airflows used are arranged in closed loops, in order to prevent leakage of air between sample flow and either closed loop flow through the membrane. The closed loops should be tight and of good quality, to avoid leaks developing over time.

The actual dryer described here is used for an instrument measuring cloud droplet size distributions, the droplet aerosol analyser (DAA) (Martinsson, 1996). The DAA requires typical cloud droplets to be transported by a flow vertically into and inside the dryer, at least until dried to submicrometer-sized droplets or particles, in order to mini- mize droplet losses due to impaction. Such losses prevent us from using any ordinary type of valve before the drying process, and we have thus chosen a straight vertical path from the inlet through the dryer. Further details of the inlet situated above the dryer are found in Frank et al. (2004). The dryer considered consists of two concentric, cylindrical stainless steel mesh metal nets (wire diameter $0.35 \mathrm{~mm}$, open area $2.25 \mathrm{~mm}^{2}$ ) (see Fig. 1), with the sample flow in the middle between these. On the other sides of the metal nets are two cylindrical membranes (inner and outer membrane tube). The plastic fiber mats (see below) supporting these membranes face towards the metal nets and the aerosol flow. Two separate closed loop dry airflows circulate on each of the other sides of the membrane tubes, achieving the transfer of humidity from the sample flow due to the humidity gradient (pumps used are model $6025 \mathrm{se} / 12 \mathrm{vdc}$, Thomas, USA). The metal nets reduce electrostatic charging of the membranes and are fixed and grounded to the stainless steel main housing of the dryer, and also act to stabilise the membranes mechanically (Ogren et al., 1985).

As a design criterion a sufficient transfer rate of water vapour is required to maintain the dried sample flow below a user-specified maximum RH. This specified RH and the minimum expected temperature of the dried sample flow define the maximum allowed specific humidity tolerated, after drying. The ambient corresponding parameters to consider for this criterion are the estimated maximum ambient $\mathrm{RH}$ and 
Table 1. Characteristics of the two tubes used in the DAA dryer, and resulting characteristics for the aerosol flow space in between, at sample flow $5.5 \mathrm{~L} \mathrm{~min}^{-1}\left(0.33 \mathrm{~m}^{3} \mathrm{~h}^{-1}\right)$. For that sample flow a dry airflow of at least 5 and $6.5 \mathrm{~L} \mathrm{~min}^{-1}$ for the inner and outer side is recommended.

\begin{tabular}{|c|c|c|c|}
\hline Parameters & Inner tube, inner flow & Outer tube, outer flow & Sample flow/air space \\
\hline GORE-TEX order number & Industrial dry filtration bag & Industrial dry filtration bag & - \\
\hline (tubes, welded at seam) & $43274327 \mathrm{c} 53-0415$ & $43274327 \mathrm{~T} 67-0415$ & - \\
\hline Diameter $[\mathrm{mm}]$ & $D_{\text {Outer }}: 53.2$ & $D_{\text {Inner }}: 67.2$ & - \\
\hline Length [mm] & $415( \pm 3)$ & $415( \pm 3)$ & 405 \\
\hline Area, effective $\left[\mathrm{m}^{2}\right]$ & 0.058 & 0.076 & 0.134 \\
\hline Airflow $\left[\mathrm{L} \mathrm{min}^{-1}\right]$ & 5 & 6.5 & 5.5 \\
\hline Width [mm] & - & - & 12 \\
\hline Top cross-section $\left[\mathrm{m}^{2}\right]$ & - & - & 0.0011 \\
\hline Airflow velocity $\left[\mathrm{m} \mathrm{s}^{-1}\right]$ & 0.13 & 0.12 & 0.084 \\
\hline Residence time $[\mathrm{s}]$ & 3 & 3.3 & 5.5 \\
\hline Reynolds number [-] & 71 & 64 & 78 (laminar) \\
\hline
\end{tabular}

the maximum ambient temperature (i.e. the maximum ambient specific humidity), at times when drying is required. The difference between these two values of specific humidities determines the transfer rate of water vapour required, for a given sample flow. This transfer rate, in turn, determines the area of the membrane $\left(A_{\text {mem }}\right)$ needed, and as well defines the drying airflow rate required, which takes up the humidity. We used GORE-TEX membrane due to performance, flexibility in fabrication options and dimensions, as well as having former experience with this type (Weingartner et al., 2002). The GORE-TEX membrane itself is thin and fragile and must be fixed on a holding surface, such as textile or plastic fiber mat (we chose plastic). For our setup, tests we made (at $294 \mathrm{~K}$ ) resulted in a practical water vapour transfer coefficient, $k$, of $4.6 \times 10^{-7} \mathrm{~kg} \mathrm{~m}^{-2} \mathrm{~s}^{-1} \% \mathrm{RH}^{-1}$ from the humid to the dry side, defined as the amount of water vapour passing $1 \mathrm{~m}^{2}$ membrane per s per $\% \mathrm{RH}$ difference between the two sides of the membrane. \% RH is chosen as the unit here as that is most readily available during measurements. The transfer rate for a membrane can vary substantially with temperature, due to physical changes in the microstructure of the membrane material, influencing its porosity. The dryer has a total effective area of $0.134 \mathrm{~m}^{2}$ (see Table 1).

Once the area of the membrane has been chosen, several design geometries can be proposed. One can envisage for instance a maximum distance from a sample air streamline to the dry airflow in order to avoid too large inhomogeneities in humidity in the sample flow, as well as a simpler geometry than ours, with only one layer of membrane used (one tube, with aerosol in the middle and dry air on the outside; however, then practical limitations on length might occur for a given drying capacity). Further design geometry considerations are outside the scope of this paper. However, there are three further design criteria to be considered once the area is determined: limitations of diffusion and impaction losses (e.g. von der Weiden et al., 2009), electrostatic losses (Fuchs, 1989) and residence time needed for drying. These will be briefly described in the following three sections. The cri- teria could be less stringent if only submicrometer aerosol were dried, or one criterion might require more attention, such as diffusion losses if nanoparticles should be studied, for instance.

\subsubsection{Diffusion/impaction losses}

The purpose of the DAA is to measure submicrometer aerosol down to a minimum dry size, $D_{\mathrm{p}}$, of about $50 \mathrm{~nm}$. For $D_{\mathrm{p}} 50 \mathrm{~nm}$ particles, the fraction penetrating the dryer due solely to diffusion losses (from top to bottom, tubing afterwards not included) is larger than $99.7 \%$ according to theoretical calculations, which is acceptable. We used the equation describing diffusional losses under laminar conditions, i.e. the transport efficiency (Willeke and Baron, 2005):

$\eta_{\text {diff }}=e^{(-\xi S h)}$

where $S h$ is the Sherwood number; the dimensionless diffusion parameter, $\xi=\pi D L / Q$, where $D$ is the particle diffusion coefficient, $L$ is the tube length and $Q$ is the flow rate. On the other hand for 3-nm-diameter particles, if that were the aim of a study, the fraction penetrating is theoretically only about $87 \%$, where an improvement would require optimal flow rate (towards limit of turbulence) and shortest possible dryer length, for a specified required drying capacity. For particles larger than $D_{\mathrm{p}} 50 \mathrm{~nm}$, diffusion losses are negligible for many applications, but for supermicron particles impaction and sedimentation losses become important. When the dryer is used in the DAA, the flow field arrangement allows cloud droplets to be transported vertically into the cross-section between the two membranes, where they dry out (see below) and become residual particles. The residual particle size distribution is measured and is typically in submicrometer-size (depending on measurement site), with low losses as mentioned above. If supermicrometer-sized dry aerosol particles were a topic of a study, the exit of a dryer and the following tubing used in relevant instrumentation would require careful design (design tactics: straight, vertical 


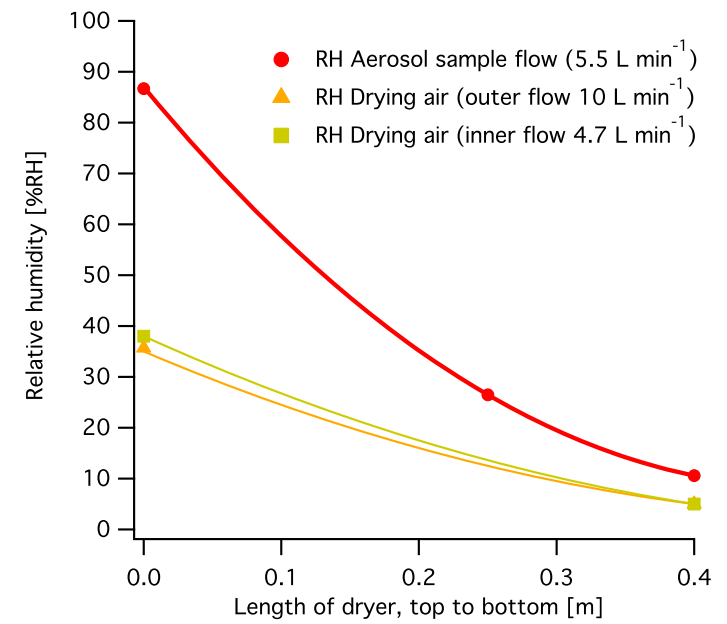

Fig. 2. $\mathrm{RH}$ profiles inside the dryer. Points are measurements, lines a guide to the eye, assuming a logarithmic function describing the water vapour removal.

and few diameter contractions); see von der Weiden et al. (2009).

\subsubsection{Electrostatic losses}

The GORE-TEX membrane is made of highly resistive PTFE (teflon) and as such can acquire electrostatic charging locally inside the dryer. Static charging would result in an electric field, which would influence charged aerosol particles with a force, causing them to move. Assuming the charge is situated at a point on the membrane wall, the particle trajectory would be affected, and if arriving at the dryer wall would mostly be deposited there; i.e. this process would result in a lower fraction of aerosol particles penetrating. Collisions with other (neutral, or larger, with lower mobility) aerosol particles would during this transport be negligible, due to the often low total concentrations in the DAA. In order to reduce electrostatic charging and thus to reduce the resulting electric field in the dryer, grounded metal nets are fitted on both sides facing the sample flow (see above). Furthermore, if the particles are charged, they might themselves create an electric field (Fuchs, 1989) resulting in particle movements, called electrostatic scattering. Measurements done in laboratory confirmed that no significant $(<5 \%)$ losses of accumulation mode sized particles occur for up to 1000 charges on each single particle and relevant concentrations in the dryer, which was also noted by Martinsson (1996).

\subsubsection{Residence time}

Residence time needed to dry the largest ambient droplets that contain relevant aerosol for the study in question must be guaranteed. Otherwise the losses, especially for the larger aerosol particles, will increase by impaction and sedimentation. For instance for the DAA system, the inlet can sample
Table 2. Example calculation of droplet evaporation time for pure water at lab conditions and 50\% RH (from www.aerosols.wustl. edu/AAARworkshop08/software/AEROCALC-11-3-03.xls, the AeroCalc by Paul Baron).

\begin{tabular}{ll}
\hline Parameters & \\
\hline Temperature $[\mathrm{K}]$ & 293.15 \\
Vapour diffusion coefficient $\left[\mathrm{m}^{2} \mathrm{~s}^{-1}\right]$ & 0.000024 \\
Vapour molecular weight $\left[\mathrm{kg} \mathrm{mol}^{-1}\right]$ & 0.018 \\
Saturation ratio $[-]$ & 0.5 \\
Initial particle diameter $[\mu \mathrm{m}]$ & 25 \\
Particle density $\left[\mathrm{kg} \mathrm{m}^{-3}\right]$ & 1000 \\
Saturation vapour pressure $[\mathrm{hPa}]$ & 23.4 \\
Temperature at drop surface $[\mathrm{K}]$ & 286.5 \\
Vapour pressure at drop surface $[\mathrm{hPa}]$ & 15.4 \\
Time to droplet evaporation $[\mathrm{s}]$ & 1.09 \\
\hline
\end{tabular}

up to approximately $25 \mu \mathrm{m}$ diameter droplets. These droplets should have enough residence time to be dried before entering various tubing and instrumentation after the dryer in order to reduce transport losses. Droplet residuals can however be supermicron, and such large particles are difficult to sample, increasingly with increasing size. Assuming a $25 \mu \mathrm{m}$ water droplet, the total droplet evaporation time needed can be calculated to $1.09 \mathrm{~s}$ at $293 \mathrm{~K}$ (see Table 2). The average residence time in the dryer is $5.5 \mathrm{~s}$, and the $\mathrm{RH}$ is below $50 \%$ more than half that time (see Fig. 2). The drying time necessary increases significantly if the RH surrounding the aerosol particle is higher. Further, at lower temperature, for instance at $273 \mathrm{~K}$ the corresponding total drying time required is $3.0 \mathrm{~s}$, approaching the limit of the system.

Further, surfactants (creating a surface layer - during the drying process) or sparingly soluble organics (that precipitate during the drying process) might reduce the vapour pressure of water from the diluted droplet (e.g. Shulman et al., 1996; Shantz et al., 2003). These effects are reduced as the supermicron size increases; thus the beginning of drying of a $25 \mu \mathrm{m}$ droplet should be unhindered by such processes. It is important to reach accumulation mode size inside the dryer to avoid losses during onwards transport of the aerosol particles/drops. The last equilibration to dry particles at instrumentation RH (often $<30 \% \mathrm{RH}$ ) can generally be done in tubing and additional volumes, if required, after the dryer, simply by the added residence time. Furthermore the sample flow is laminar; thus the center streamline flow velocity is approximately twice the average. Consequently, the center streamline has half the average residence time. If more drying time is required, the dryer must be larger, or the flow smaller. We use an additional modular section with the same flange for increased residence time in this case. The two abovementioned requirements of minimum diffusion losses (increases with time) vs. residence time for drying (increasing time is advantageous) need to be balanced. The two can 
in many situations be characterised and corrected for, to some extent.

\subsection{Design - generation of dry air}

The dry air came from circulation through aluminium oxide $\left(\mathrm{Al}_{2} \mathrm{O}_{3}\right)$ pellets (spherical diameter $2-4 \mathrm{~mm}$ ) (Martinsson et al., 1992). Each container had $1 \mathrm{~kg} \mathrm{Al}_{2} \mathrm{O}_{3}$. The $\mathrm{Al}_{2} \mathrm{O}_{3}$ pellets were dried, regenerated, with low-pressure (about $4 \mathrm{hPa}$ ) evaporation drying, alternating between two containers (see left side of Fig. 1). A membrane vacuum pump was in constant use to generate the low pressure (Vacuubrand model MV 2NT, Germany). Two $0.002 \mathrm{~m}^{3}$ stainless steel containers were used for each drying flow used (i.e. 4 in total, in two pairs), each pair alternating in either regenerating mode or supplying dry air after the airflow had passed the $\mathrm{Al}_{2} \mathrm{O}_{3}$ pellets (at ambient pressure). The switching was done with three-way impulse solenoid valves. At the moment the valves switch, initially the low pressure from the container just having been dried is connected to the inlet volume. To avoid a large pressure change, two vacuum vent valves, which open if pressure is less than ca. $500 \mathrm{hPa}$, were fitted, one on each of the drying airflow circuits (see Fig. 1). The switching of the main dryer valves can be set when different conditions are met, such as if the aerosol RH is too high, or if the RH in the drying branches is too high. We used as a condition that the dryer (both branches simultaneously) should switch if the $\mathrm{RH}$ of the outer drying airstream was larger than $17 \%$, measured at its approximately ambient temperature (in an outdoor metal box) before entering the drier at the lower port. Further we used a minimum time between switching, which was set to $20000 \mathrm{~s}$ (about $5.5 \mathrm{~h}$ ), and in addition the switch was done only at end of a measurement cycle. During ambient conditions close to $100 \% \mathrm{RH}$, the system switched constantly at the minimum time interval. Following a switch the system waited $30 \mathrm{~s}$ before next measurement started again, in order to minimise any disturbances.

\subsection{Aerosol particle transmission and vapour transfer characterisation}

In order to characterise the aerosol transmission through the dryer, measurements were done comparing the aerosol concentration at the exit of the dryer, $C_{\text {exit }}$, with that at the entry, $C_{\text {in }}$. Concentrations were measured with condensation particle counters (CPCs, Model 7610, TSI, USA). The CPCs had a lower detection limit of $15 \mathrm{~nm}$ (Hermann and Wiedensohler, 2001). The upper limit is $>3 \mu \mathrm{m}$ according to the manual. For the largest sizes studied, it would have been advantageous to use an optical particle sizer. Nevertheless, we included all measured data below. The transmission was defined as $C_{\text {exit }} / C_{\text {in. }}$. Particles in the range $D_{\mathrm{p}} 0.03-4.9 \mu \mathrm{m}$ were evaluated. The setup can be seen in Fig. 3. Firstly a vibrating orifice aerosol generator (VOAG, model 3450, TSI, USA) was used to produce dry (RH $30 \%$ ) ammonium sul-

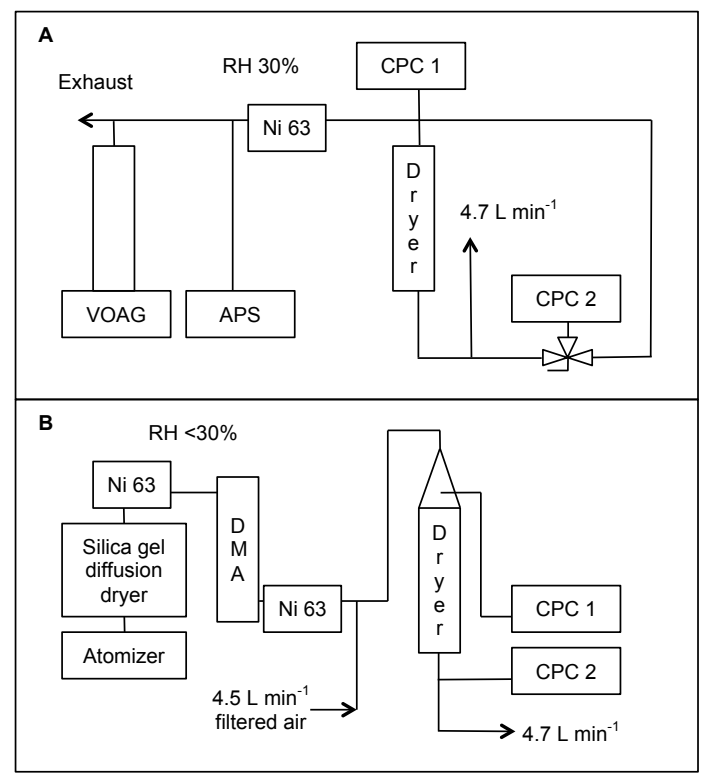

Fig. 3. Experimental setups for transmission measurements. In (A) the vibrating orifice aerosol generator (VOAG) is shown, aerosol particle sizer (APS), neutralizer (Ni 63). 2 CPCs were used, each with a flow of $1 \mathrm{~L} \mathrm{~min}^{-1}$, similar in (B), showing the setup with an atomizer, for submicron-sized particles. A larger cone was used on top of the dryer, from where the sample flow to CPC 1 was drawn. The flow through the dryer was $5.7 \mathrm{~L} \mathrm{~min}^{-1}$ for both setups.

phate (AS, p.a.) particles, from a solution in Milli-Q water, ranging from geometric diameter $\left(D_{\text {geo }}\right) 0.84$ to $4.9 \mu \mathrm{m}$. The aerodynamic diameter, $D_{\text {aero }}$, was measured with an aerosol particle sizer (APS, TSI model 3321) and was converted to $D_{\text {geo }}$ under assumption of spherical particles according to $D_{\text {geo }}=D_{\text {aero }} / \sqrt{\rho}$, where $\rho$ is particle density $\left(1770 \mathrm{~kg} \mathrm{~m}^{-3}\right.$ for AS). The aerosol was neutralised with a ${ }^{63} \mathrm{Ni}$ source (case design at Lund University, serial number KF11, source model NB14, 555 MBq, 2008, QSA Global, USA). This was in order to reduce the electrostatic losses and to only test sedimentation and impaction losses in this experiment. The particles were fed directly into the dryer, with a four-way connector, connected to a first CPC, and a second CPC measured the concentration after the dryer. The second CPC thus had two additional $90^{\circ}$ bends in the experimental setup, which resulted in supermicron particle losses from the setup for these VOAG tests (see below).

Secondly, smaller sized AS particles were produced with a TSI atomizer (TSI 3076 model), ranging from dry mobility diameter 0.03 to $0.4 \mu \mathrm{m}$. The aerosol was neutralised, in order to achieve a known charge distribution (Wiedensohler, 1988), and a monomodal size was selected with a Vienna type DMA (differential mobility analyzer, sheath and aerosol flow rates of 9.8 and $2.2 \mathrm{~L} \mathrm{~min}^{-1}$ ) and then neutralised again. The second source reduced the double charged particles passing the DMA, in order to reduce electrostatic losses as mentioned above. However, the second source was redundant 
for these experiments (within measurement uncertainty). The aerosol flow was diluted via a filter with a low-pressure drop for a total sample flow rate of $6.7 \mathrm{~L} \mathrm{~min}^{-1}$. During these experiments, a metal cone was used upstream the dryer, with a port where the first CPC sampled $1 \mathrm{~L} \mathrm{~min}^{-1}$, and the second CPC measured the concentration after the dryer $\left(1 \mathrm{~L} \mathrm{~min}^{-1}\right)$. The remaining $4.7 \mathrm{~L} \mathrm{~min}^{-1}$ were exhausted, with a valve as critical orifice, to the vacuum system in the laboratory, for a total flow of $5.7 \mathrm{~L} \mathrm{~min}^{-1}$ passing through the dryer.

Further experiments in order to estimate the vapour transfer property of the membrane were performed. Humidity was produced by bubbling air through Milli-Q water in an impinger, heated to lab temperature, which was $294 \mathrm{~K}$ (as the water otherwise cools due to evaporation). The sample air entered with $87 \% \mathrm{RH}$, measured with a capacity RH sensor (HygroClip S, Rotronic). The Rotronic sensor had an accuracy of $1.5 \% \mathrm{RH}$ and $0.3 \mathrm{~K}$. The $\mathrm{RH}$ inside the dryer was investigated by inserting a small tube, extracting a small airflow (corresponding to the area of the tube compared to total cross-sectional area of dryer) and measuring the RH of this small flow at lab temperature.

The water vapour transfer coefficient $k$ was used to describe membrane performance (Bierwerth, 2001):

$k=\left(\dot{m}_{\mathrm{H}_{2} \mathrm{O}}\right) /\left(A_{\text {mem }} \Delta \mathrm{RH}_{\mathrm{log}}\right)$

where $\dot{m}_{\mathrm{H}_{2} \mathrm{O}}$ is the transfer rate of water vapour $\left(\mathrm{kg} \mathrm{s}^{-1}\right.$, using $0.015 \mathrm{~kg} \mathrm{~kg}^{-1} \mathrm{H}_{2} \mathrm{O}$ in the dry air at $10^{5} \mathrm{~Pa}$ ), $A_{\mathrm{mem}}$ is the membrane surface and $\Delta \mathrm{RH}_{\log }$ is the logarithmic mean difference in $\mathrm{RH}$, defined as

$\Delta \mathrm{RH}_{\log }=\frac{\left(\Delta \mathrm{RH}_{\mathrm{Max}}-\Delta \mathrm{RH}_{\mathrm{Min}}\right)}{\ln \left(\frac{\Delta \mathrm{RH}_{\mathrm{Max}}}{\Delta \mathrm{RH}_{\mathrm{Min}}}\right)}$,

where $\Delta \mathrm{RH}_{\mathrm{Max}}$ and $\Delta \mathrm{RH}_{\mathrm{Min}}$ are the differences of $\mathrm{RH}$ at each side of the dryer, maximum and minimum of these, respectively.

\subsection{Ambient measurements}

The dryer was used for continuous long-term measurements at the summit of the mountain Brocken $\left(51.80^{\circ} \mathrm{N}, 10.67^{\circ} \mathrm{E}\right.$, $1142 \mathrm{~m}$ a.s.l.) in the Harz region in central Germany. The $\mathrm{RH}$ at ambient temperature $\left(T_{\mathrm{amb}}\right)$ directly after the exit of the dryer $\left(\mathrm{RH}_{\text {dried }}\right)$ was evaluated by using a Rotronic capacity RH sensor. However, this sensor measured the sample aerosol $\mathrm{RH}\left(\mathrm{RH}_{\text {station }}\right)$, inside the measurement station (at its temperature, $T_{\text {station }}$ and in a small side-flow from a tee in the main sample flow). This reading was converted to $\mathrm{RH}_{\text {dried }}$ as follows. The vapour pressure $\left(p_{\mathrm{H}_{2} \mathrm{O}}^{\text {station }}, \mathrm{Pa}\right)$ in the sample flow is defined as

$p_{\mathrm{H}_{2} \mathrm{O}}=\frac{\mathrm{RH}_{i}}{100} p_{\text {sat }}$

where $p_{\text {sat }}$ is the saturation vapour pressure of water, calculated from the following empirical formula (Weingartner et al., 1997):

$p_{\text {sat }}=610.8 e^{\left(5350\left(\frac{1}{273.15}-\frac{1}{T_{i}}\right)\right)}$,

with $T_{i}$ in $\mathrm{K}$ and $i=$ station. The above vapour pressure equation was confirmed with the Magnus equation (e.g. Murray, 1967), with a deviation of $\leq 0.1 \%$ in the range $273-293 \mathrm{~K}$. That same vapour pressure is then used in the above equations, rearranged, to calculate the $\mathrm{RH}_{\text {dried }}$, at $T_{\mathrm{amb}}$ (assuming isobaric cooling without condensation).

Furthermore the ambient $\mathrm{RH}\left(\mathrm{RH}_{\mathrm{amb}}\right)$ was measured (sensor model GHTU.SGT010, Greisinger, Germany). The difference between the ambient water vapour flow into the system and the water vapour flow after the dryer is the water vapour removed from the sample flow (denoted $\dot{m}_{\text {dried }}, \mathrm{kg} \mathrm{s}^{-1}$ ). This was calculated according to

$\dot{m}_{\text {dried }}=x_{\text {ambient }} \dot{m}_{\text {ambient }}-x_{\text {station }} \dot{m}_{\text {station }}$,

where $\dot{m}_{i}$ and $x_{i}$ are the mass flow of dry air $\left(\mathrm{kg} \mathrm{s}^{-1}\right)$ and specific humidity $\left(\mathrm{kg} \mathrm{kg}^{-1}\right)$ for the ambient sample flow and the sample flow conditioned inside the station, respectively. $\dot{m}_{\text {ambient }}$ and $\dot{m}_{\text {station }}$ are identical and represent the dry airflow through the system. The density changes up to $10 \%$ at occasions between these conditions.

\section{Results}

Here we present tests from the laboratory, aiming to describe the dryer under controlled conditions, as well as long-term results from the field, showing the overall performance of the dryer.

\subsection{Laboratory measurements}

The transmission through the dryer from entry to exit is shown in Fig. 4. An average transmission for accumulation mode particles $\left(D_{\mathrm{p}} 0.1-1 \mu \mathrm{m}\right)$ of $99.9 \%$ was observed. The transmission decreases with decreasing particle size below $0.1 \mu \mathrm{m}$. The Particle Loss Calculator (von der Weiden et al., 2009) was used to model losses in the dryer (thick line in figure). This software is described in the open access publication, and "employs relevant empirical and theoretical relationships found in established literature". For supermicronsized particles from the VOAG, the transmission decreases due to two additional $90^{\circ}$ bends situated after the dryer in the experimental setup. These bends do not need to be used during actual measurements in the field. The two bends can be accounted for (modelled with the thin grey line in Fig. 4) and indicate the importance of designing a proper exit from the dryer, should large particles be studied.

The uncertainty in transmission as shown in Fig. 4 is composed of counting statistics (Poisson error), flow settings (pressure changes) and dilution (leaks). The Poisson error was $\leq 1 \%$ for the accumulation mode sizes measured; the 


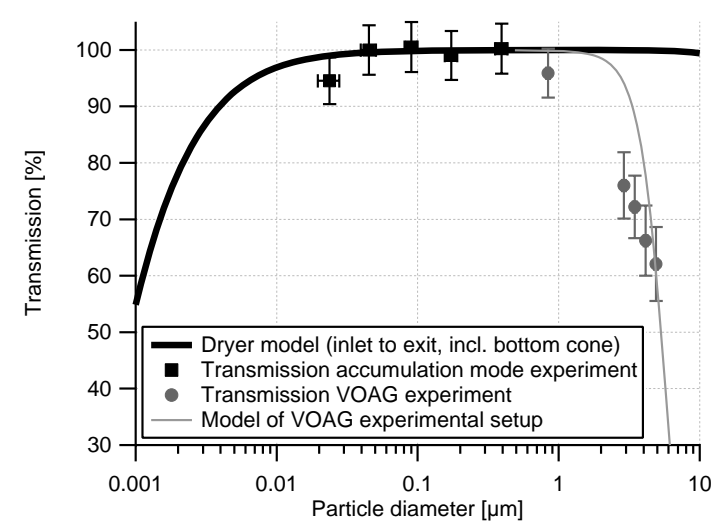

Fig. 4. Transmission through dryer at $5.7 \mathrm{~L} \mathrm{~min}^{-1}$ sample flow. Particles were neutralised (i.e. negligible electrostatic scattering). Concentrations tested varied between $1-3500 \mathrm{~cm}^{-3}$. Thick line is model of transmission through dryer. The measurements showing low transmission above $1 \mu \mathrm{m}$ are due to two $90^{\circ}$ bends in the experimental setup. The experiments were performed with dry conditions, $30 \%$ RH.

error in flows was estimated to $\leq 3 \%$ and dilution $\leq 3 \%$, giving a total error of $4.4 \%$. The uncertainty in transmission increases with increasing particle size, due to mainly lower particle concentrations generated. The uncertainty in size is $3 \%$ for the VOAG setup (standard deviation between size deduced from VOAG settings and measured size from APS) and estimated to be $\leq 10 \%$ for the atomizer DMA setup (from uncertainty in dimensions, flows and high voltage supply for the DMA).

The water vapour transfer of the dryer was tested in the laboratory, geometry of dryer as described above. Humidity was produced by bubbling air through Milli-Q water in an impinger, heated to lab temperature. $\mathrm{RH}$ of $10.6 \%$ at the dryer exit was achieved in the air sample flow with $5.5 \mathrm{~L} \mathrm{~min}^{-1}\left(0.33 \mathrm{~m}^{3} \mathrm{~h}^{-1}\right)$. In Fig. 2 measured RHs are shown. The lines to guide the eye are based on the assumption of a logarithmic dependence of $\mathrm{RH}$ along the dryer (Bierwerth, 2001). The sample flow between the two concentric membranes is surrounded by two closed loop drying flows (the outside flow rate being $10 \mathrm{~L} \mathrm{~min}^{-1}$ and the inside (inner dry flow) being $4.7 \mathrm{~L} \mathrm{~min}^{-1}$ ). The total drying airflow is approximately three times as large as the sample flow. During these laboratory tests the flow ratio of the drying air (outside/inside) was 2.1 , which was set too high. The a priori most favourable flow ratio, for a symmetrical drying effect, should be the ratio of the areas of the membranes, which is 1.3 . During the operation in the field, the flows where 5.0 and $3.7 \mathrm{~L} \mathrm{~min}^{-1}$, outer and inner respectively, and the ratio was 1.4 .

$\Delta \mathrm{RH}_{\log }$ was 20.6 and $19.9 \% \mathrm{RH}$ for the outer and inner dry airflow, respectively. The water vapour transfer coefficient $k$ was calculated from Eq. (2) to be $4.6 \times 10^{-7} \mathrm{~kg} \mathrm{~m}^{-2} \mathrm{~s}^{-1} \% \mathrm{RH}^{-1} . k$ can be compared to the manufacturer's specification and literature values of approximately $8-13 \times 10^{-7} \mathrm{~kg} \mathrm{~m}^{-2} \mathrm{~s}^{-1} \% \mathrm{RH}^{-1}$ (Huang and Qian, 2007), for the membrane, and it is probable that we obtain a significantly lower value due to membrane support structure and metal nets fitted, which reduce the water vapour transfer.

\subsection{Long-term ambient measurements}

The dryer was used for continuous long-term measurements at the summit of the mountain Brocken $\left(51.80^{\circ} \mathrm{N}, 10.67^{\circ} \mathrm{E}\right.$, $1142 \mathrm{~m}$ a.s.l.) in the Harz region in central Germany from May to October 2010. The project is in collaboration with the Air Chemistry Group of the Technical University of Brandenburg (BTU Cottbus), who has had a cloud measurement site at mount Brocken for many years.

The average $\mathrm{RH}_{\text {dried }}$ during this time period (the measurements at Brocken) was $26.6 \pm 7.3 \% \mathrm{RH}$ (one standard deviation). Average $T_{\text {ambient }}$ was $282.4 \mathrm{~K}$ and average $T_{\text {station }}$ was $296 \mathrm{~K}$. The $\mathrm{RH}_{\text {dried }}$ is the quality criterion to ensure a sufficient dry sample flow for the drying of droplets. Furthermore, a second criterion for the highest allowable RH inside instrumentation in the station can be defined, primarily in order to deal with situations when the outdoor part of the instrument is warmer than the indoor part. In our case we considered data with $\mathrm{RH}_{\text {dried }}<30 \% \mathrm{RH}$ to be used as is.

The specific humidity can be calculated as

$x_{i}=\frac{M_{\mathrm{H}_{2} \mathrm{O}}}{M_{\mathrm{Air}}}\left(\frac{p_{\mathrm{H}_{2} \mathrm{O}}}{P_{\mathrm{amb}}-p_{\mathrm{H}_{2} \mathrm{O}}}\right)$,

where $M_{\mathrm{H}_{2} \mathrm{O}}$ and $M_{\text {Air }}$ are the molecular masses of water and air, respectively. $P_{\text {amb }}$ is the ambient pressure and $p_{\mathrm{H}_{2} \mathrm{O}}$ is calculated from the measured $\mathrm{RH}$ and temperature (station) with Eqs. (4) and (5). The sample mass flow of dry air relates to the volume flow (continuously monitored in the instrument) as follows:

$\dot{m}_{\text {station }}=\rho_{\text {air }} Q_{\text {samplestation }}$,

where $\rho_{\text {air }}$ is the density of air (at $P_{\text {amb }}$ and at $T_{\text {station }}$ ) and $Q_{\text {samplestation }}$ is the dry aerosol sample flow. The above assumes the dried volume sample flow to be similar to the dry airflow, which are within $0.5 \%$ up to $293 \mathrm{~K}$ and $30 \% \mathrm{RH}$. The maximum $\dot{m}_{\text {dried }}$ achieved was $1.2 \times 10^{-6} \mathrm{~kg} \mathrm{~s}^{-1}$. Furthermore the fog/cloud droplet water is also removed, which is of lesser quantity, and if included would slightly increase the calculated water vapour removed from the system. The fog/cloud droplet entering the dryer can be estimated to rarely exceed $0.002 \mathrm{~kg} \mathrm{~m}^{-3}$ (with an example cloud of 500 cloud droplets $\mathrm{cm}^{-3}$, with diameter $20 \mu \mathrm{m}$ ). Generally the specific humidity at the site was in the range 0.005 $0.02 \mathrm{~kg} \mathrm{~m}^{-3}$.

During these measurements the RHs of the dry airflows were not measured. Thus the logarithmic mean RH was not known, so we could not relate the water vapour transfer to the performance of the membrane measured in the laboratory. The drying capacity, $\dot{m}_{\text {dried }}$, represents what was 


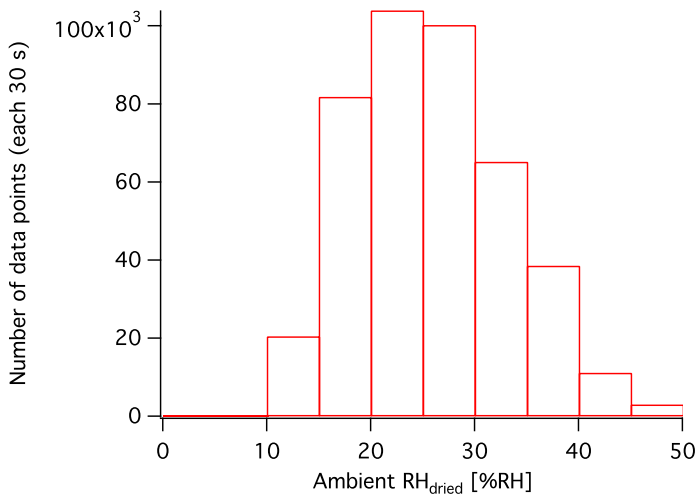

Fig. 5. Histogram of $\mathrm{RH}_{\text {dried }}$, i.e. air sample $\mathrm{RH}$ after drying. $72 \%$ of the time the RH was below $30 \%$. The $T_{\text {station }}$ range was $285-$ $307 \mathrm{~K}$, the $T_{\text {ambient }}$ range $270.6-301 \mathrm{~K}$ and $\mathrm{RH}_{\text {ambient }}$ range $9.5-$ $100 \%$ during the measurements. Approximately 140 days of data.

achieved in the field and corresponds to drying a $5.7 \mathrm{~L} \mathrm{~min}^{-1}$ $\left(0.35 \mathrm{~m}^{3} \mathrm{~h}^{-1}\right)$ aerosol sample flow from 100 to $27 \% \mathrm{RH}$ at $293 \mathrm{~K}$ (with a drying air total flow of $8.7 \mathrm{~L} \mathrm{~min}^{-1}$ ).

The percentage of the time the system operated was $94.2 \%$. Some of the downtime was due to planned maintenance of the system; thus the reliability of the dryer was higher than this. During October the inlet and dryer also automatically shut down a few occasions due to freezing and icing conditions. The time fraction that the dryer resulted in a sample RH below $30 \%$ was $72.2 \%$, from 9 May until 20 October 2010, when data were available (see Fig. 5). We investigated possible reasons for the spread of $\mathrm{RH}_{\text {dried }}$, such as variations in ambient vapour pressure, $T_{\mathrm{amb}}$, diurnal variations and longer time series; however, no single factor influenced the results. Specifically, the RH after the dryer virtually depends on neither ambient nor laboratory temperature. The ambient RH is not a good indicator for performance, because the water removed reduces at colder temperatures. However, the water vapour removed from the sample flow increases linearly with the ambient water vapour pressure, indicating that the system can dry air up to at least the humidities measured during these field tests.

\section{Discussion}

Although the dryer worked without failures during the field measurement period, on occasions the $\mathrm{RH}_{\text {dried }}$ was above $30 \%$, which should be improved. No single environmental factor has been found to limit the system, but rather a combination of factors contributes to time periods with $\mathrm{RH}_{\text {dried }}$ above $30 \%$. Thus a general improvement is required. There are two major refinements to do with the drying system presented. The first is to supply a higher dry airflow on the outside of the GORE-TEX membranes. We were presently limited to pumps that were slightly too close to design criteria (regarding flow, durability and ambient cold conditions).
That improvement should reduce the sample RH. Secondly the drying circuits (the $\mathrm{Al}_{2} \mathrm{O}_{3}$ containers specifically) were also situated outdoors at cold conditions, and as these are regenerated, they cool further. If these circuits were to be situated indoors, or heated, the regeneration process would be more efficient. Indoor placement of the pumps would also be beneficial for durability. However, this would require adjustments depending on ambient and indoor temperature differences, in order to achieve a constant flow. The dry airflow can vary to some extent, without hampering the drying process.

Currently, the regulation of the switching of dryers was when the RH in the drying airflow increased above a threshold value, as mentioned above. This would be improved by using $\mathrm{RH}_{\text {dried }}$ of the sample at $T_{\mathrm{amb}}$. The threshold for switching could then be set directly at a defined sample RH, for instance $25 \%$. In addition a criterion for the indoor RH in the instrument should be used, which when exceeded should also switch dryers.

\section{Conclusions}

A dryer designed for continuous sampling of atmospheric aerosol, where a specified relative humidity of the sample flow (lower than the atmospheric humidity) is required, has been designed and tested. The specific purpose of the dryer presented here is to dry fog/cloud droplets (maximum diameter approximately $25 \mu \mathrm{m}$, highly charged, up to $5 \times 10^{2}$ charges) with minimum losses of droplets and particles from entrance to exit of the dryer. The accumulation mode particle transmission was measured to be independent of particle size and $99.9 \%$, corresponding well with theory.

The water vapour transfer coefficient $k$ was measured to be $4.6 \times 10^{-7} \mathrm{~kg} \mathrm{~m}^{-2} \mathrm{~s}^{-1} \% \mathrm{RH}^{-1}$ in the laboratory (temperature $294 \mathrm{~K}$ ) and is used for design purposes.

The system was tested from 9 May until 20 October 2010, on the mountain Brocken $\left(51.80^{\circ} \mathrm{N}, 10.67^{\circ} \mathrm{E}, 1142 \mathrm{~m}\right.$ a.s.1.) in the Harz region in central Germany. A maximum water vapour transfer rate of $1.2 \times 10^{-6} \mathrm{~kg} \mathrm{~s}^{-1}$ was achieved, corresponding to drying from 100 to $27 \% \mathrm{RH}$ at $293 \mathrm{~K}$ for a $5.7 \mathrm{~L} \mathrm{~min}^{-1}\left(0.35 \mathrm{~m}^{3} \mathrm{~h}^{-1}\right)$ aerosol sample flow. This can be improved with a closed loop higher dry airflow and warming of the dry air generation system, in order to achieve a more effective dry air regeneration, in our case. The sample flow was below $30 \%$ relative humidity $72 \%$ of that time period. Measurements were done $>94 \%$ during the deployment in the field, and the dryer functioned all that time.

Acknowledgements. Thanks to S.-I. Cederfelt for discussions on the humidity transfer process; thanks to J. Hjelmroth (W. L. Gore \& Associates Scandinavia AB, Gothenburg, Sweden) for professional advice on the choice of membrane, support material as well as making drawings and ordering, and to C. Nilsson for putting the UTEbox with the drying containers and auxiliary equipment together. 
The postdoc grant (decision 2007) from LTH, Lund University, Sweden, for Staffan Sjogren is gratefully acknowledged. Funding from The Swedish Research Council for Environment, Agricultural Sciences, and Spatial Planning (FORMAS), The Swedish Research Council (VR), and The Crafoord Foundation are gratefully acknowledged.

We thank Detlev Möller, Wolfgang Wieprecht, Karin Acker, Dieter Kalass and Jürgen Hofmeister, Brandenburg Technical University, Cottbus, Germany, for help and support with the field station Brocken.

Many thanks to the editor and several reviewers who helped in improving the quality of this paper.

Edited by: J.-P. Putaud

\section{References}

Bierwerth, W.: Tabellenbuch Chemietechnik, 2nd Edn., EuropaLehrmittel, Haan-Gruiten, 2001.

Frank, G. P., Cederfelt, S.-I., and Martinsson, B. G.: Characterisation of a unipolar charger for droplet aerosols of $0.1-20 \mu \mathrm{m}$ in diameter, J. Aerosol Sci., 35, 117-134, 2004.

Fuchs, N. A.: The Mechanics of Aerosols, republication edition, edited by: Davies, C. N., Dover Publications, New York, 1989.

Hermann, M. and Wiedensohler, A.: Counting efficiency of condensation particle counters at low-pressures with illustrative data from the upper troposphere, J. Aerosol Sci., 32, 975-991, 2001.

Huang, J. and Qian, X.: A new test method for measuring the water vapour permeability of fabrics, Meas. Sci. Technol., 18, 30433047, 2007.

Martinsson, B. G.: Physical basis for a droplet aerosol analysing method, J. Aerosol Sci., 27, 997-1013, 1996.

Martinsson, B. G., Hansson, H.-C., Asking, L., and Cederfelt, S.I.: A relative humidity processing method for the sampling of aerosol particles with low growth-ability, Tellus B, 44, 632-644, 1992.
Murray, F. W.: On the computation of saturation vapor pressure, J. Appl. Meteorol., 6, 203-204, 1967.

Ogren, J. A., Heintzenberg, J., and Charlson, R. J.: In-situ sampling of clouds with a droplet to aerosol converter, Geophys. Res. Lett., 12, 121-124, 1985.

Shantz, N. C., Leaitch, W. R., and Caffrey, P. F.: Effect of organics of low solubility on the growth rate of cloud droplets, J. Geophys. Res., 108, 4168-4177, 2003.

Shulman, M. L., Jacobson, M. C., Carlson, R. J., Synovec, R. E., and Young, T. E.: Dissolution behavior and surface tension effects of organic compounds in nucleating cloud droplets, Geophys. Res. Lett., 23, 277-280, 1996.

Tuch, T. M., Haudek, A., Müller, T., Nowak, A., Wex, H., and Wiedensohler, A.: Design and performance of an automatic regenerating adsorption aerosol dryer for continuous operation at monitoring sites, Atmos. Meas. Tech., 2, 417-422, doi:10.5194/amt-2-417-2009, 2009.

von der Weiden, S.-L., Drewnick, F., and Borrmann, S.: Particle Loss Calculator - a new software tool for the assessment of the performance of aerosol inlet systems, Atmos. Meas. Tech., 2, 479-494, doi:10.5194/amt-2-479-2009, 2009.

Weingartner, E., Burtscher, H., and Baltensperger, U.: Hygroscopic properties of carbon and diesel soot particles, Atmos. Environ., 31, 2311-2327, 1997.

Weingartner, E., Gysel, M., and Baltensperger, U.: Hygroscopicity of aerosol particles at low temperatures, 1. New low-temperature H-TDMA instrument: Setup and first applications, Environ. Sci Technol., 36, 55-62, 2002.

Wiedensohler, A.: An approximation of the bipolar charge distribution for particles in the submicron size range, J. Aerosol Sci., 19, 387-389, 1988.

Willeke, K. and Baron, P.: Aerosol Measurement: Principles, Techniques, and Applications, Van Nostrand Reinhold, New York, 2005. 